\title{
D614G mutation and SARS-CoV-2: impact on S-protein structure, function, infectivity, and immunity
}

\author{
Manojit Bhattacharya ${ }^{1} \cdot$ Srijan Chatterjee ${ }^{2}$. Ashish Ranjan Sharma ${ }^{3} \cdot$ Govindasamy Agoramoorthy $^{4}$. \\ Chiranjib Chakraborty ${ }^{2}$ (1)
}

Received: 13 September 2021 / Revised: 1 November 2021 / Accepted: 1 November 2021 / Published online: 10 November 2021

(c) The Author(s), under exclusive licence to Springer-Verlag GmbH Germany, part of Springer Nature 2021

\begin{abstract}
The progression of the COVID-19 pandemic has generated numerous emerging variants of SARS-CoV-2 on a global scale. These variants have gained evolutionary advantages, comprising high virulence and serious infectivity due to multiple spike glycoprotein mutations. As a reason, variants are demonstrating significant abilities to escape the immune responses of the host. The D614G mutation in the S-glycoprotein of SARS-CoV-2 variants has shown the most efficient interaction with the ACE2 receptor of the cells. This explicit mutation at amino acid position 614 (aspartic acid-to-glycine substitution) is the prime cause of infection and re-infection. It changes the conformation of RBD and cleavage patterns S-glycoprotein with higher stability, replication fitness, and fusion efficiencies. Therefore, this review aims to provide several crucial pieces of information associated with the D614 mutational occurrence of SARS-CoV-2 variants and their infectivity patterns. This review will also effectively emphasize the mechanism of action of D614G mutant variants, immune escape, and partial vaccine escape of this virus. Furthermore, the viral characteristic changes leading to the current global pandemic condition have been highlighted. Here, we have tried to illustrate a novel direction for future researchers to develop effective therapeutic approaches and counterweight strategies to minimize the spread of COVID-19.
\end{abstract}

\section{Key points}

- D614G mutation arises within the S-glycoprotein of significant SARS-CoV-2 variants.

- The D614G mutation affects infection, re-infection, cleavage patterns of S-glycoprotein, and replication fitness of SARSCoV-2 variants.

- The D614G mutation influences the immunity and partial vaccine escape.

Keywords D614G mutation · Variants $\cdot$ S-glycoprotein $\cdot$ Mutational changes $\cdot$ SARS-CoV-2

Manojit Bhattacharya and Srijan Chatterjee contributed equally to this work

Govindasamy Agoramoorthy

agoram@tajen.edu.tw

$\triangle$ Chiranjib Chakraborty drchiranjib@yahoo.com

1 Department of Zoology, Fakir Mohan University, Vyasa Vihar, Balasore 756020, Odisha, India

2 Department of Biotechnology, School of Life Science and Biotechnology, Adamas University, Barasat-Barrackpore Rd, Kolkata, West Bengal 700126, India

3 Institute for Skeletal Aging and Orthopaedic Surgery, Hallym University-Chuncheon Sacred Heart Hospital, Chuncheon-si 24252, Gangwon-do, Republic of Korea

4 College of Pharmacy and Health Care, Tajen University, Yanpu, Pingtung 907, Taiwan

\section{Introduction}

The SARS-CoV-2 infections cause a quick increase of COVID-19 cases to develop a severe risk to human health worldwide. Hence, it is vital to understand the virus's mutational changes and rapid evolution. It is also crucial to know the impact of novel vaccine development, diagnostic tests, antiviral drugs pathogenesis, resistance, and immune responses (Chellapandi and Saranya 2020; Sanjuán and Domingo-Calap 2016). So, continuous monitoring and accurate analysis of the evolutionary phenomenon of SARS$\mathrm{CoV}-2$ are crucial to distinguish the definite genetic changes and variations leading to the virulence and transmissibility of the virus (Leopold and Busby 2020; Mercatelli and Giorgi 2020). During the SARS-CoV-2 virus outbreak, the 
genetic variations have evolved at a faster rate. Within several variations, a conversion of the A (adenine) nucleotide at genome locus of 23,403 to a G (guanine) occurred, and it has been recognized as the most prevalent clade SARSCoV-2 virus (Korber et al. 2020b). Such nucleotide changes arose in March 2020 at a low frequency, but they became rapidly extended and considered an utmost infinite clade by April-May 2020. It also offered an advantage of selective fitness during the outbreaks. A report showed that the spike glycoprotein with G at the position of 614 (S-G614) linking maximum viral loads was noted in the upper respiratory tract of infected patients with low disease severity (Korber et al. 2020b). It is also noted that engineered viruses ensuring S-G614 also show a significant infection rate than the viruses with S-D614 (Clay et al. 2014; Plante et al. 2021). This mutation is localized in the exterior part of the RBD (receptor binding domain) region of the spike glycoprotein (Fig. 1). Therefore, the same affinities for binding S-D614 and S-G614 to the ACE2 (angiotensin-converting enzyme 2) receptor were also reported (Yurkovetskiy et al. 2020; Zhang et al. 2020a). Significantly, the convalescent sera from COVID-19 patients might neutralize the mutated S-D614 and the S-G614-pseudotyped viruses with equivalent efficacies (Korber et al. 2020b; Weissman et al. 2021).

A research report supported the chances that the D614G nucleotide substitution confers higher infectivity and transmissibility without better binding affinities to ACE2 receptors or over increased escape of immune surveillance mechanisms (Cheng et al. 2021). It is also essential that multiple characteristic changes are observed in SARS-CoV-2 variants due to the D614G mutant (Table 1). Explaining the mechanism of higher infectivity by D614G mutation containing SARS-CoV-2 virus is critical to understanding the prevalence for developing an effective treatment approach for virus-infected patients.

In this manuscript, we have discussed the D614G mutation using different points, such as the distribution of D614G mutation in all significant variants of this virus. An implication of the mutation in different variants such as B.1.1.7

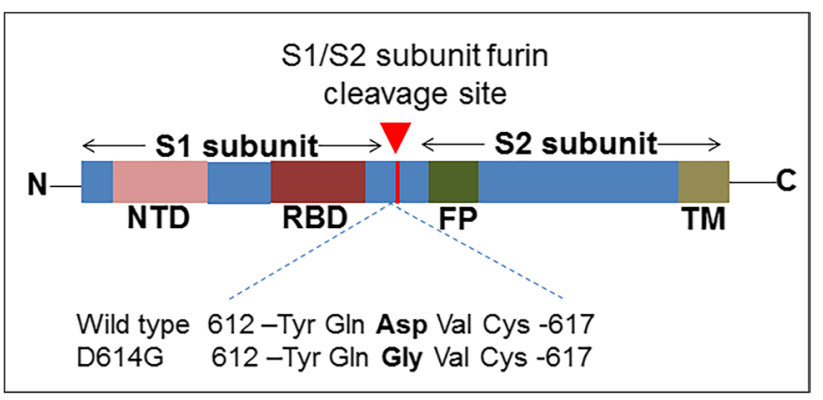

Fig. 1 Schematic diagram of the location of D614G amino acids where mutation occurs in S-glycoprotein (alpha) variant, B.1.351 (beta) variant, P.1 (gamma) variant, B.1.525 (eta) variant, B.1.526 (iota) variant, P.2 variant, and B.1.427/B.1.429 (epsilon) variants has also been illustrated. Moreover, we have discussed the D614G mutation that helps in the infectivity and re-infectivity. The molecular mechanism of action of D614G mutant variants is illustrated very extensively. Finally, we demonstrate the immune escape and partial vaccine escape due to this mutation.

At the same time, to illustrate the molecular mechanism of action of D614G mutant variants, we have presented some essential points which are first, D614G mutant and RBD conformation; second, S-protein cleavage pattern and D614G mutation; third, S-protein stability and D614G mutation; fourth, D614G mutation and S-protein volume; and fifth, D614G mutation activity on human ACE2 receptor protein.

\section{The presence of D614G far and wide}

The majority of the SARS-CoV-2 genome contained the aspartic acid in spike protein's $614^{\text {th }}$ position depicting the trimeric structure in a closed form (Fig. 2), as reported till February 2020. Since then, the prevalence of G614 has been noticed in the SARS-CoV-2 isolates (Daniloski et al. 2021). According to the GISAID's EpiCoV database, $72 \%(22,103)$ of the SARS-CoV-2 genome analysis highlighted the presence of G614 mutation by early June 2020 (Shu and McCauley 2017). Within a short tenure, the G614 mutation became particularly dominant worldwide (Table 2) (Hadfield et al. 2018). According to epidemiological reports, the WHO classified the variants under two categories: the variant of interest (VOI) and the variant of concern (VOC). The CDC also followed the same. The VOIs and VOCs are classified based on viral transmission rate, virulence, vaccine efficacy, etc. (Aleem et al. 2021; Chakraborty et al. 2021). These variants originating from a different country of SARS-CoV-2 have shown the sequence similarity of S-protein, which contains D614G mutation (Table 3).

\section{Implication of D614G in B.1.1.7 (alpha) variant}

The D614G mutation in the S-protein is predominant in the virus inhabiting the upper respiratory tract. This mutation has been observed in most SARS-CoV-2 isolates worldwide (Korber et al. 2020b; Yurkovetskiy et al. 2020). Another extremely virulent strain with the presence of D614G mutation is B.1.1.7, and it was first reported in the UK (Peters et al. 2021). The D614G mutation results in forming a structural cavity between $\mathrm{S} 1$ and $\mathrm{S} 2$ interface in B.1.1.7 variant, contributing to its high transmission efficiency. However, the 
Table 1 Characteristics changes of SARS-CoV-2 between the wild-type strain and D614G mutant variant

\begin{tabular}{|c|c|c|c|c|}
\hline Sl. No & $\begin{array}{l}\text { Several characteristics of the } \\
\text { SARS-CoV-2 virus }\end{array}$ & D614 at S-protein & G614 at S-protein & Reference \\
\hline 1 & $\begin{array}{l}\text { Binding affinity with the ACE2 } \\
\text { receptor }\end{array}$ & Lesser than G614 & Much more greater than D614 & (Ozono et al. 2021) \\
\hline 2 & Spike protein density & Less & More & (Zhang et al. 2020a) \\
\hline 3 & Spike protein stability & Less stable & $\begin{array}{l}\text { Greater stability compared to } \\
\text { D614 }\end{array}$ & (Jackson et al. 2021) \\
\hline 4 & Spike protein cleavage pattern & $\begin{array}{l}\text { Less resistant to cleavage than } \\
\text { the G614 }\end{array}$ & More resistant to cleavage & (Daniloski et al. 2021) \\
\hline 5 & Conformation of the RBD & Confirmation varies from G614 & $\begin{array}{l}\text { Preferably stays in the open } \\
\text { conformation }\end{array}$ & (Yurkovetskiy et al. 2020) \\
\hline 6 & Infectivity rate & Lower than the mutant strain & Much higher & (Zhang et al. 2021) \\
\hline 7 & Disease severity & Same in both the variants & Same in both the variants & $\begin{array}{l}\text { (Korber et al. 2020b; Volz et al. } \\
\text { 2021) }\end{array}$ \\
\hline 8 & Mortality rate & Same in both the variants & Same in both the variants & (Volz et al. 2021) \\
\hline 9 & $\begin{array}{l}\text { RMSD study of S-protein after } \\
\text { interaction with ACE2 recep- } \\
\text { tor }\end{array}$ & $1.09 \pm 0.04 \mathrm{~nm}$ & $1.26 \pm 0.1 \mathrm{~nm}$ & (Kwarteng et al. 2021) \\
\hline 10 & $\begin{array}{l}\text { RMSF study of S-protein after } \\
\text { interaction with ACE2 recep- } \\
\text { tor }\end{array}$ & Less flexible compared to G614 & Structurally more flexible & (Kwarteng et al. 2021) \\
\hline 11 & Replication fitness & Lower than G614 & Greater & $\begin{array}{l}\text { (Hou et al. 2020; Korber et al. } \\
\text { 2020b; Yurkovetskiy et al. } \\
\text { 2020; Zhang et al. 2020a) }\end{array}$ \\
\hline 12 & S1 domain shedding & Greater shedding & $\begin{array}{l}\text { The shedding is reduced com- } \\
\text { pared to D614 S }\end{array}$ & (Zhang et al. 2020a) \\
\hline 13 & $\begin{array}{l}\text { Stability of the } \mathrm{S} 1 \text { and } \mathrm{S} 2 \\
\text { interface }\end{array}$ & Less stable than G614 & Much more stabilized & (Fernández 2020) \\
\hline 14 & Retention of S1 subunit & $\begin{array}{l}\text { Lesser retention compared to } \\
\text { G614 }\end{array}$ & Have more retention capacity & (Zhang et al. 2020a) \\
\hline 15 & Viral load & Lower than G614 & Higher & $\begin{array}{l}\text { (Korber et al. 2020b; Volz et al. } \\
\text { 2021) }\end{array}$ \\
\hline 16 & Fusion efficiency & Lower than G614 & Higher & (Zhang et al. 2021) \\
\hline
\end{tabular}

D614G mutation also accelerates the spike protein cleavage into $\mathrm{S} 1$ and $\mathrm{S} 2$ domains, hindering the contact between the separate chains of the spike protein complex. It also results in a robust structural rearrangement enhancing the invading capacity of this variant into the respiratory epithelial host cells (Fig. 3). This mutation also reduces the intermolecular attraction between the two subunits (S1 and S2) of the D614G strain. The D614G mutation site also serves as an effective tool for designing vaccines against B.1.1.7 strain with a very high transmissibility rate (Ostrov 2021).

\section{Effect of D614G in B.1.351 (beta) variant}

The beta variant (B.1.351), also known as the beta strain, was isolated from South Africa at the end of 2020 (Tegally et al. 2021). This variant includes several mutations, including D614G. As discussed earlier, a common characteristic of this mutation is increased transmissibility; the B.1.351 strain is also reported to be highly virulent. The B.1.351 binds to the ACE2 receptor strongly (Mwenda et al. 2021; Wibmer et al. 2021). The additional mutations in the B.1.351 strain highlight that there might be some molecular basis of evolution, which is yet to be confirmed (Slavov et al. 2021), and it contributes to a greater virulence of the strain. The D614G mutation in B.1.351 variant also alters its binding affinity with hACE2 (human angiotensin-converting enzyme 2 ) and brings about some changes in antibody neutralization (Zhou et al. 2021b).

\section{Importance of D614G in P.1 (gamma) variant}

The gamma variant (P.1) had shown the maximum number of mutations in the spike glycoprotein compared to other variants. D614G in the spike protein outside the RBD is also present (Harvey et al. 2021; Wang et al. 2021a). This variant was first reported in Brazil at the end of 2020 and 
Fig. 2 D614G mutation location in the 3D model of S-glycoprotein and different conformational states of S-glycoprotein. A 3D model of S-glycoprotein stating the location of D614G mutation. B Open conformation of S-glycoprotein. C Closed conformation of S-glycoprotein. Researchers noted that D614G mutation favors the open conformation of S-glycoprotein and thus helps more interaction with the hACE2 receptor, which causes more infection and reinfection

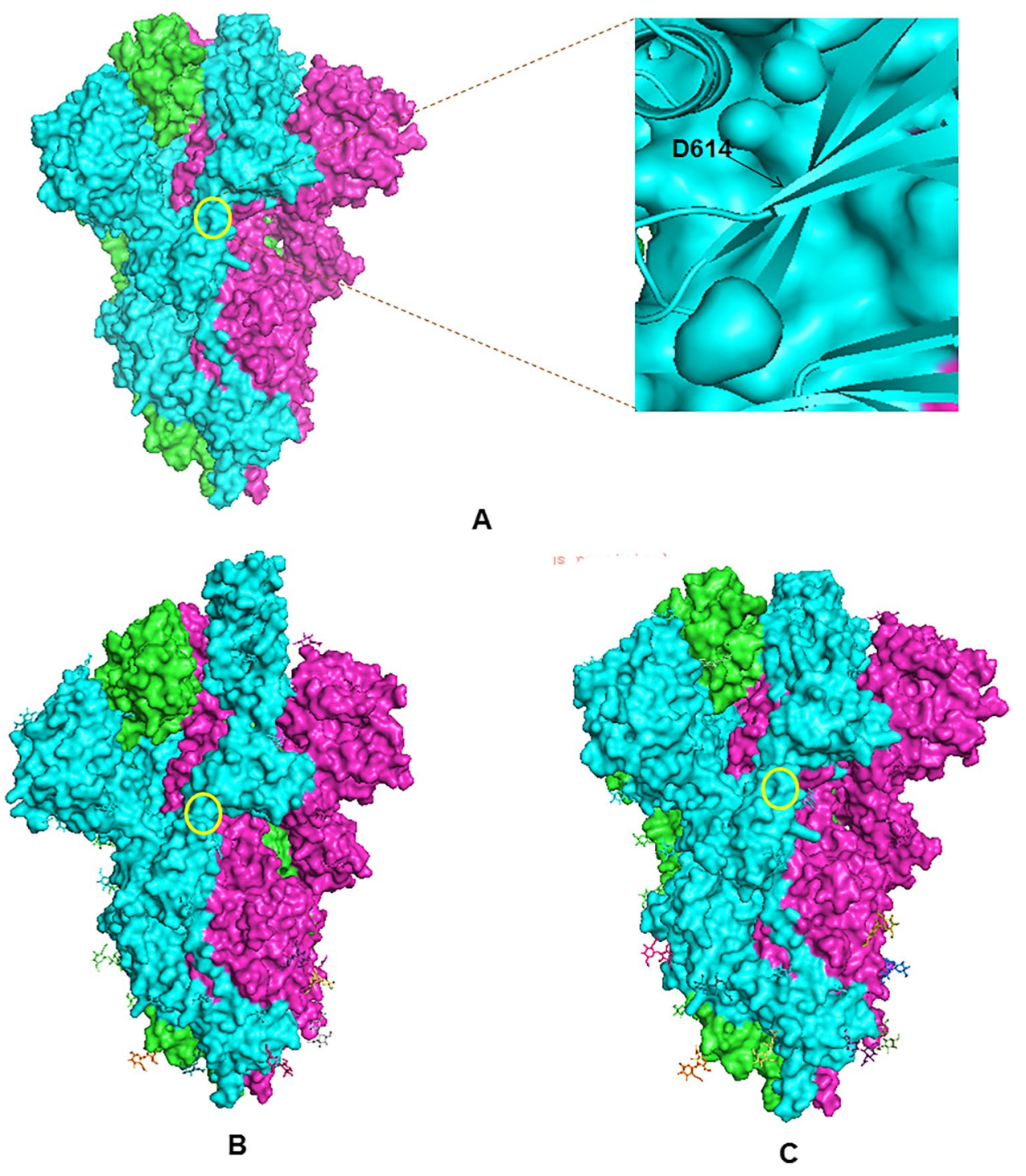

in the USA in January 2021 (Faria et al. 2021). Due to the prevalence of the D614G mutation, there is an alteration in the RBD conformation, maintaining it in an open state and an increased affinity of the variant towards the ACE2 receptor contributes to its high transmission rate.

\section{Significance of D614G in B.1.525 (eta) variant}

The eta (B.1.525) is an emerging and significant variant highlighted by the WHO when it was first reported in the USA in December 2020. This strain also possesses several mutations, notably in the S-protein, of which D614G is common. This strain only contains a single mutation in the RBD (Chakraborty et al. 2021). Eta variant demonstrates alteration in the neutralization post-vaccination and antibody treatment (Janik et al. 2021). It shows a greater transmissibility rate and virulence, a common characteristic of the D614G mutation. These characteristics affect the effectiveness of vaccines and therapeutics used for treating COVID-19 infection. It is also considered to be responsible for community infection (World Health Organization 2021; Sharun et al. 2021). Moreover, it alters the B.1.525 virion replication inside the host cells (Zhou et al. 2021a).

\section{Association of D614G in B.1.526 (iota) variant}

The iota (B.1.526) variant was isolated from the USA in November 2020. It replaces aspartic acid residue in the 614 th position, and it has a significant impact on vaccine efficacy and therapeutics. As a consequence, it is known to be very detrimental to public health (West et al. 2021). On June 22, 2021, the WHO declared it as the "VOI" 
Table 2 Data showing the country-wise frequency and date of the first report of the D614G mutant variant of SARS-CoV-2 worldwide

\begin{tabular}{|c|c|c|c|}
\hline SL. No & Country name & $\begin{array}{l}\text { Frequency of } \\
\text { D614G mutation }\end{array}$ & Date of first report \\
\hline 1 & India & 20,224 & 2020-01-12 \\
\hline 2 & Bangladesh & 1214 & 2020-04-08 \\
\hline 3 & Australia & 13,177 & 2020-01-25 \\
\hline 4 & Iran & 205 & 2020-01-06 \\
\hline 5 & Italy & 30,944 & 2020-02-06 \\
\hline 6 & South Africa & 4676 & 2020-01-05 \\
\hline 7 & USA & 350,909 & 2020-01-03 \\
\hline 8 & Spain & 32,590 & $2020-02-14$ \\
\hline 9 & South Korea & 5372 & 2020-09-05 \\
\hline 10 & United Kingdom & 222,274 & 2020-01-05 \\
\hline 11 & Brazil & 20,254 & $2020-02-25$ \\
\hline 12 & China & 314 & 2020-01-24 \\
\hline 13 & Mexico & 12,134 & 2020-01-02 \\
\hline 14 & New Zealand & 775 & 2020-03-02 \\
\hline 15 & Netherlands & 38,331 & 2020-01-08 \\
\hline 16 & Pakistan & 181 & 2020-05-03 \\
\hline 17 & Canada & 55,714 & 2020-01-01 \\
\hline 18 & Germany & 109,212 & 2020-02-08 \\
\hline 19 & England & 148,620 & 2020-02-03 \\
\hline 20 & Japan & 61,596 & 2020-02 \\
\hline
\end{tabular}

Source: https://coval.ccpem.ac.uk/mutations

Table 3 Sequence similarity of S-protein from different mutant variants of SARS-CoV-2, containing D614G mutation

\begin{tabular}{lllc}
\hline SL. No & Name of the variant & Origin & $\begin{array}{l}\text { Similarity with } \\
\text { D614G variant } \\
(\%)\end{array}$ \\
\hline 1 & B.1.525 & UK/Nigeria & 0.25 \\
2 & B.1.526 & USA & 0.94 \\
3 & B.1.617.1 & India & 0.21 \\
4 & B.1.617.2 & India & 12.59 \\
5 & P.2 & Brazil & 0.17 \\
6 & P.3 & Philippines/Japan & 0.01 \\
7 & B.1.427 & USA & 0.64 \\
8 & B.1.1.7 & UK & 35.40 \\
9 & B.1.351 & South Africa & 0.99 \\
10 & B.1.427 & USA & 0.64 \\
11 & P.1 & Japan/Brazil & 2.30 \\
\hline
\end{tabular}

Source: https://cov-spectrum.ethz.ch

due to its potential to decrease neutralization efficiency, enhanced transmission efficiency, and virulence (Aleem et al. 2021). Notwithstanding the fact, we can conclude by seeing the characteristics of this variant that the D614G spike mutation plays a potential role in dominating these characteristics in this variant. These are some of the standard features possessed by the D614G variant.

\section{Importance of D614G in P.2 (zeta) variant}

Similar to B.1.525 and B.1.526, the P.2 variant has been kept in the category of "VOI" by the WHO due to its potential effect in antibody neutralization. The P.2 (zeta) variant was first reported from Brazil in April 2020 (Aleem et al. 2021). The zeta variant has few mutations, and D614G in the S-protein outside the RBD is common among them (Chakraborty et al. 2021).

\section{Impact of D614G in B.1.427/B.1.429 (epsilon) variant}

The B.1.427/B.1.429 (epsilon) variants were isolated from California, USA. The B.1.427 has a single mutation in the trimeric spike complex, namely, D614G, and it falls under the VOC category by the CDC and VOI by the WHO. The B.1.429 variant had some other mutations in the spike protein besides D614G. It was called VOI by both CDC and WHO. These variants have shown their extreme contagious nature. Due to similar mutations with the other strains, this variant also possesses the same immune and partial vaccine escape property (McCallum et al. 2021).

\section{D614G mutation and infectivity}

One of the common reasons for the SARS-CoV-2 re-infection could be the mutation of D614 to G614, as highlighted from the SARS-CoV-2 genome sequencing (Amorim et al. 2021). This mutation in the spike protein proved to be more infectious. In this mutation, the G614 indicated a higher affinity towards the ACE2 receptor and more extensive incorporation of the spike protein into the host genome (Zhang et al. 2020b). Zhang et al. also elucidated that the mutation of the aspartic acid with glycine at the 614th position is more stable and thus has a greater contagious rate. Two patients in Iran were reinfected with the virus, and the genome sequencing results indicated the D614G mutation. However, both of them did not have severe symptoms, although being affected with the mutant strain (Salehi-Vaziri et al. 2021). Another series of cases reported from Brazil also implicated the same data. The signs were not variable to a greater extent for the second time (Amorim et al. 2021). Despite the stable nature of the mutation, no noticeable symptoms were seen in the case of re-infection (Korber et al. 2020a; Zhang et al. 2020c). According to Zhang et al., the possible reason could be due to the greater incorporation of 
Fig. 3 The schematic diagram illustrates the D614G mutation causing more infectivity. Due to this mutation, the S-protein volume increases and causes more infections

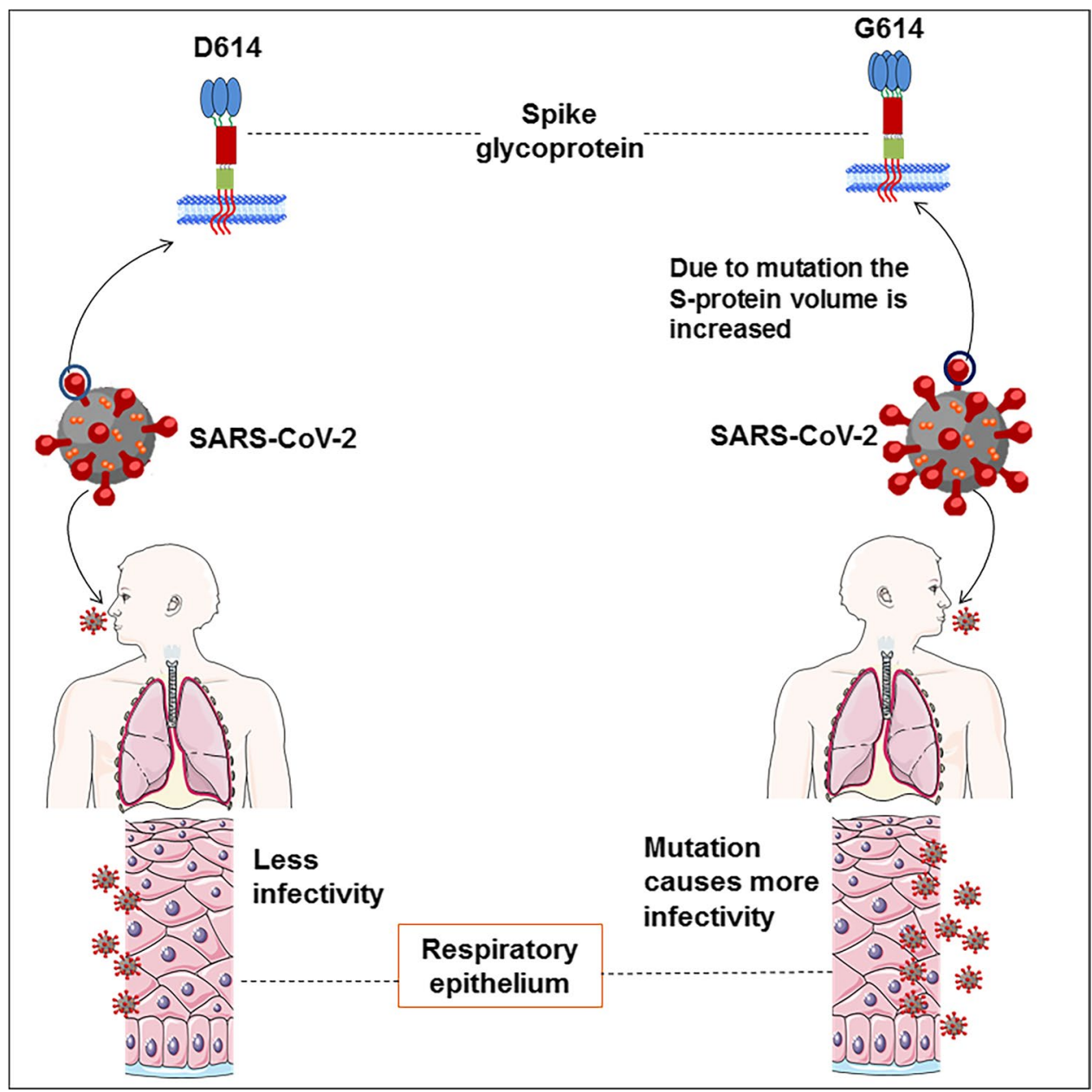

the spike protein into the host genome leading to more transmission. Nonetheless, due to some parameters, the replication inside the host was prevented to some extent. Moreover, the mutation favored to a greater extent in species inhabiting a furin-cleavage site (Zhang et al. 2020b). The cleavage at the furin site promoted the transmission to a greater extent in viral replication (Cheng et al. 2021).

\section{Molecular mechanism of action of D614G mutant variants}

The elucidated molecular mechanism lying behind the D614G mutation is yet to be explored. Certain factors based on the mutation can be explained, and they include the cleavage pattern of the spike protein, the conformation of the RBD, volume of spike protein incorporated, and strength (Fig. 3) (Jackson et al. 2021). The mutation takes place in spike protein, and as a result, it may affect the binding efficiency to the ACE2 receptor. Zhang L et al. provided plasmon resonance data implying that the $\mathrm{S}$-trimeric complex of D614 and G614 shows a similar binding affinity with the
ACE2 receptor (Zhang et al. 2020a). Another group of scientists made the same conclusion using the bio-layer interferometry technique (Daniloski et al. 2021).

\section{RBD conformation and D614G mutation}

According to Gobeil et al., the cryo-electron microscopic structure elucidated that the G614 variant had an altered conformation of the RBD region, which makes it highly efficient in cleaving the furin site (Gobeil et al. 2021). This cleavage, in turn, regulates the ratio of the RBD in the spike ectodomain and induces an allosteric effect on its position. Although the D614G mutation site is distant from the RBD, it still alters activity in the mutant variants. Mansbach and his colleagues have performed molecular dynamics simulation highlighting the $\mathrm{D} 614 \mathrm{G}$ results in an open conformation of the RBD. The open-up conformation of the RBD enables the virus to infect the host because the closed conformation does not permit the ACE2 and RBD interaction (Mansbach et al. 2021). According to Weissman et al., 84\% of the S-protein in the G614 strain are in "one-up" conformation and the 
rest "three-down" conformation (Weissman et al. 2021). The open-up conformation of the RBD in the D614G mutant strain contributes to its enhanced transmissibility into the host cells (Korber et al. 2020b). The glycine mutation at the 614th position disrupts the formation of a salt bridge between D614 and lysine residue (K854), which allows the RBD to be in the open state in the G614 variant (Cai et al. 2020; Xiong et al. 2020; Zhang et al. 2021; Zhou et al. 2020).

\section{S-protein cleavage pattern and D614G mutation}

Structurally, the S-protein is a trimeric complex. Its cleavage by a furin protease gives an $S 1$ subunit, which contains the $\mathrm{RBD}$, and the fusion complex S1/S2 at the cell surface mediates the viral entry into the host cell. The S-protein cleavage in the D614G strain interferes with the confirmation of the RBD, resulting in reduced shedding of the $\mathrm{S} 1$ subunit. The open conformation of the RBD in this mutant enhances its transmissibility (Yurkovetskiy et al. 2020; Zhang et al. 2020a). Another novel discovery made while modulating the S-protein cleavage pattern was the site for elastase cleavage (Bhattacharyya et al. 2020; Hu et al. 2020).

Moreover, the G614 variant also possesses a more efficient cleavage at the furin site than the D614 (Gobeil et al. 2020). Daniloski et al. also reported that the G614 mutant is more insusceptible in cleavage phenomena of the S-protein than the D614 (Daniloski et al. 2021). However, Spike 614 is located next to the fusion peptide, which is somewhat near the protease cleavage site. This fact highlights the variation in the tendency or requirement of the TMPRSS2 to cleave the spike glycoprotein in the G614 strain (Korber et al. 2020b).

\section{S-protein stability and D614G mutation}

The G614 S-protein is more stable than the D614 SA cryoEM data provided by Zhang et al., which elucidated that in the G614 Spike trimeric complex, there is a residue near the CTD2 region, which is highly oriented compared to D614. This orientation makes the G614 Spike structurally flexible, and it forms a loop, packaging the S trimer between CTD1 and NTD. The structural flexibility also helps in closing the hydrophobic region of the CTD2 domain. As a result, the S1 domain shedding is reduced (Zhang et al. 2021). It is the primary reason behind the S-protein stability in the G614 mutant. The other factors which play an essential role in S-protein stability are the interaction stability between the two domains (namely S1 and S2), the stronger interparticle attraction between the molecules of the two domains, and the greater holding capacity of the S1 domain (Fernández 2020; Zhang et al. 2020b). Mahmoudi Gomari et al. have investigated the structural stability of the spike protein in the D614G mutation using some in silico approaches and concluded that the replacement of the aspartic acid residue with glycine decreases the entropy and energy of the mutant strain compared to the wild type. The decrease is due to the incorporation of glycine, which has a very short side chain compared to aspartic acid. This, in turn, also contributes to the increase in S-glycoprotein stability in the D614G mutation (Mahmoudi Gomari et al. 2021).

\section{D614G mutation and S-protein volume}

The D614G mutation does not increase the binding efficiency of the spike protein with the ACE2 receptor. This variant's enhanced infectivity and transmissibility rate are more because of incorporating more spike protein into the virion. Incorporating a more incredible amount of spike protein results in the reduced shedding of the $\mathrm{S} 1$ domain and stabilizes the S1 and S2 domains (Zhang et al. 2020a). It has been reported that the D614G mutation does not possess greater severity of the disease, but it enhances viral fitness (Korber et al. 2020b; Zhang et al. 2020c). Several factors that make the G614 mutation more stable than the D614 are the ratio of the $\mathrm{S} 1$ and $\mathrm{S} 2$ domains is weaker in the case of D614 compared to G614. Due to the lesser volume of the spike glycoprotein in the D614 variant, the intra-host replication ability is altered compared to G614 (Zhang et al. 2020a). Moreover, the increased volume of the spike glycoprotein in the D614G mutation gives it additional characteristic features, including transmissibility, virulence, antigenicity, immune escape, and partial vaccine escape.

\section{D614G mutation and human ACE2 receptor protein}

The SARS-CoV-2 virus invades the host by the interaction of S-protein with the ACE2 receptor. Besides, the spike protein interacts with some other co-receptors (Daly et al. 2020). The D614G mutation in the spike protein increases the host-invading capability of the virus due to the strong binding with the ACE2 receptor. However, the binding affinity does not have any influence on its antigenicity (Ozono et al. 2021). The spike protein is activated after cleaving it by the TMPRSS 2 protease into two subunits, namely S1 and S2 (Belouzard et al. 2009; Hoffmann et al. 2020). The binding of the spike glycoprotein with the ACE2 receptor results in the shedding of the $\mathrm{S} 1$ domain. As a result, the $\mathrm{S} 2$ domain gets exposed (Belouzard et al. 2009). The site of the D614G mutation is situated in the carboxy-terminal of 
the S1 domain, which belongs to the exterior region of the RBD (Ogawa et al. 2020). Ozono et al. experimented with the binding affinity of the ACE2 receptor and concluded that the D614G variant has a greater binding affinity than the wild-type strain. This increased binding efficiency also makes the mutant spike protein structurally flexible (Ozono et al. 2021). The replacement of the aspartic acid residue with glycine resulted in the presence of the virus in the upper respiratory tract region, highlighting the greater infectivity rate as more viruses interact with the ACE2 receptor of epithelial cells (Fig. 3). However, the open conformation state of the spike glycoprotein does not have a more significant effect on the binding affinity with the ACE2 receptor (Mansbach et al. 2021).

\section{Immune escape and D614G}

Due to the prevalence of specific mutations in the SARSCoV-2 isolates, "immune escape" is a significant concern for scientists now (Chakraborty et al. 2021). The re-infection of COVID-19 suggests the challenging role of the host immune system in combating the virus. As the viral replication results in mutation, the preformed antibodies may not be sufficient for viral clearance (Shi et al. 2020b). The direct effect of the D614G mutation is yet to be explored. However, the replacement of a single residue will not be a worthy cause for immune escape. The alteration in the confirmation due to this mutation may somehow change the binding affinity (Koyama et al. 2020). A SARS-CoV-2 pp assay (spikepseudotyped particle) was conducted to examine the chances of immune escape due to the emergence of the D614G mutation, which insinuated the neutralizing effect of the antibodies against this mutation. This assay shows that the mutation does not significantly impact the immune escape but serves as a pivotal regulator to enhance viral fitness and transmissibility ( $\mathrm{Li}$ et al. 2020). However, Kwarteng et al. reported that the D614G alters the conformation of the spike glycoprotein towards an open state. The alteration and interaction of spike protein with antibodies suggest that the D614G mutation may elevate, drop, or bring no change in the neutralization effect as it is entirely controlled by the nature of the neutralizing antibody (Kwarteng et al. 2021).

\section{Partial vaccine escape and D614G}

The evidence of re-infection had agitated everyone worldwide, leading to the question on the efficacy of administered vaccines (Zhang et al. 2020b). All the vaccines were formulated before the emergence of the G614 mutation. The epitope prediction of the HLA alleles implicated that the mutation alters the binding of the MHC (Andreatta and
Nielsen 2016), and it had shown a remarkable change in the conformation of the RBD, resulting in decreased efficacy of vaccines. The change makes the variant more stable and increases antibody neutralization (Chi et al. 2020; Liu et al. 2020). Moreover, the mutation is a valuable tool for scientists to formulate the next-generation vaccines for the emerging strains since they became susceptible to the previously administered vaccines (Jeyanathan et al. 2020; Wang et al. 2021b, 2021c; Wu et al. 2021). This susceptibility has been proved by conducting several experiments on hamsters by analyzing the serum (Shi et al. 2020a). The remarkable change observed in the spike protein due to the alternation of the RBD conformation enhances the viral transmission but hardly changes its antigenicity (Yurkovetskiy et al. 2020). It is mainly responsible for getting a varying neutralizing effect on the antibodies due to this mutation.

\section{Conclusion}

The D614G mutant became predominant across the world within a brief period. All the mutant variants declared as VOI/VOC by the WHO and CDC had the D614G mutation common. The mutation occurs in the S-protein, yet it alters some of the conformations, giving some extra fitness to the virus. It brings many changes in the S-glycoprotein's characteristic features that make the strain predominant (Fig. 4). The evolution of this strain also raises questions regarding the efficiency of the vaccine. However, studies suggest that this strain does not have a potential role in increasing the disease severity. Still, some cases of re-infection confirmed the presence of D614G mutation in the genome of these isolates. Some alteration in the spike protein gives it an enhanced transmission rate and serves as an effective tool for scientists in developing the next-generation therapeutics for treating COVID-19. The replacement of a single amino acid might not lead to immune escape to a greater extent. Still, the presence of this mutation made some variants (P.1,

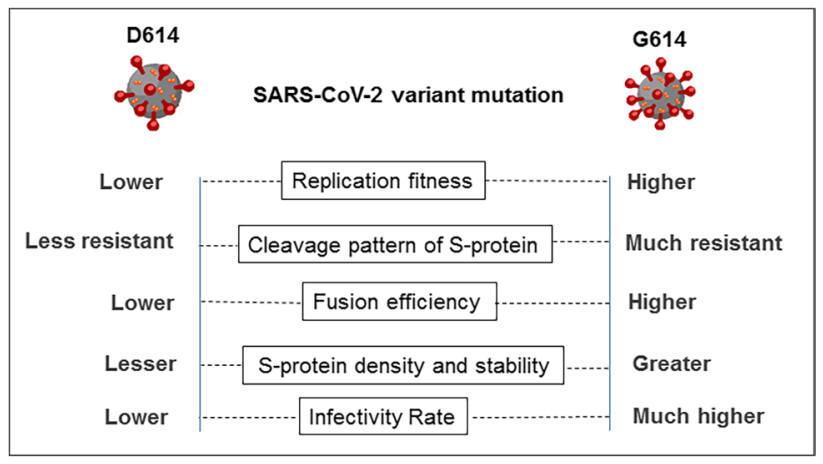

Fig. 4 A conceptual diagram illustrating the characteristics change of the SARS-CoV-2 variant due to the D614G mutation 
B.1.1.7, and B.1.427/B.1.429) more virulent. The virulence was alarming, and therefore, understanding the changes in the molecular mechanism of the variants due to D614G mutation and how it affects their virulence is a prerequisite. More studies on the changes in molecular mechanism and virulence of the variants due to the D614G mutation will help future researchers develop proper therapeutics and vaccines, helping to end the pandemic soon.

Author contribution MB convicted methodology, data curation, validation, and writing of manuscript. SC did formal analysis, validation, and writing. ARS performed the data validation, formal analysis, and editing. CC conceptualized and developed the methodology, data curation, editing, and supervision. GA did validation and final editing of the manuscript. All authors reviewed and approved the final version of the manuscript.

Data availability The authors confirm that the data supporting the findings of this study are available within the article.

\section{Declarations}

Ethics approval This article does not contain any studies with human participants or animals performed by any of the authors.

Conflict of interest The authors declare no competing interests.

\section{References}

Aleem A, AB AS, Slenker AK (2021) Emerging variants of SARSCoV-2 and novel therapeutics against coronavirus (COVID19). In: StatPearls [Internet]. Treasure Island (FL): StatPearls Publishing;

Amorim MR, Souza WM, Barros AC Jr, Toledo-Teixeira DA, DosSantos KB, Simeoni CL, Parise PL, Vieira A, Forato J, Claro IM (2021) Respiratory viral shedding in healthcare workers reinfected with SARS-CoV-2, Brazil, 2020. Emerg Infect Dis 27(6): 1737-1740

Andreatta M, Nielsen M (2016) Gapped sequence alignment using artificial neural networks: application to the MHC class I system. Bioinformatics 32(4):511-517

Belouzard S, Chu VC, Whittaker GR (2009) Activation of the SARS coronavirus spike protein via sequential proteolytic cleavage at two distinct sites. Proc Natl Acad Sci U S A 106(14):5871-5876

Bhattacharyya C, Das C, Ghosh A, Singh AK, Mukherjee S, Majumder PP, Basu A, Biswas NK (2020) Global spread of SARS-CoV-2 subtype with spike protein mutation D614G is shaped by human genomic variations that regulate expression of TMPRSS2 and MX1 genes. bioRxiv. https://doi.org/10.1101/ 2020.05.04.075911.

Cai Y, Zhang J, Xiao T, Peng H, Sterling SM, Walsh RM, Rawson S, Rits-Volloch S, Chen B (2020) Distinct conformational states of SARS-CoV-2 spike protein. Science 369(6511):1586-1592

Chakraborty C, Bhattacharya M, Sharma AR (2021) Present variants of concern and variants of interest of severe acute respiratory syndrome coronavirus 2: their significant mutations in S-glycoprotein, infectivity, re-infectivity, immune escape and vaccines activity. Rev Med Virol:e2270
Chellapandi P, Saranya S (2020) Genomics insights of SARS-CoV-2 (COVID-19) into target-based drug discovery. Med Chem Res:1-15

Cheng Y-W, Chao T-L, Li C-L, Wang S-H, Kao H-C, Tsai Y-M, Wang H-Y, Hsieh C-L, Lin Y-Y, Chen P-J (2021) D614G substitution of SARS-CoV-2 spike protein increases syncytium formation and virus titer via enhanced furin-mediated spike cleavage. Mbio 12(4):e00587-e621

Chi X, Yan R, Zhang J, Zhang G, Zhang Y, Hao M, Zhang Z, Fan P, Dong Y, Yang Y (2020) A neutralizing human antibody binds to the N-terminal domain of the Spike protein of SARS-CoV-2. Science 369(6504):650-655

Clay L, Caudron F, Denoth-Lippuner A, Boettcher B, Frei SB, Snapp EL, Barral Y (2014) A sphingolipid-dependent diffusion barrier confines ER stress to the yeast mother cell. Elife 3:e01883

Daly JL, Simonetti B, Klein K, Chen K-E, Williamson MK, AntónPlágaro C, Shoemark DK, Simón-Gracia L, Bauer M, Hollandi R (2020) Neuropilin-1 is a host factor for SARS-CoV-2 infection. Science 370(6518):861-865

Daniloski Z, Jordan TX, Ilmain JK, Guo X, Bhabha G, Sanjana NE (2021) The Spike D614G mutation increases SARS-CoV-2 infection of multiple human cell types. Elife 10:e65365

Faria NR, Mellan TA, Whittaker C, Claro IM, Candido DdS, Mishra S, Crispim MA, Sales FC, Hawryluk I, McCrone JT (2021) Genomics and epidemiology of the P. 1 SARS-CoV-2 lineage in Manaus Brazil. Science 372(6544):815-821

Fernández A (2020) Structural impact of mutation D614G in SARSCoV-2 spike protein: enhanced infectivity and therapeutic opportunity. ACS Med Chem Lett 11(9):1667-1670

Gobeil S, Janowska K, McDowell S, Mansouri K, Parks R, Manne K, Stalls V, Kopp M, Henderson R, Edwards RJ (2020) D614G mutation alters SARS-CoV-2 spike conformational dynamics and protease cleavage susceptibility at the S1/S2 junction. bioRxiv. https://doi.org/10.1101/2020.10.11.335299

Gobeil SM-C, Janowska K, McDowell S, Mansouri K, Parks R, Manne K, Stalls V, Kopp MF, Henderson R, Edwards RJ (2021) D614G mutation alters SARS-CoV-2 spike conformation and enhances protease cleavage at the S1/S2 junction. Cell Rep 34(2):108630

Hadfield J, Megill C, Bell SM, Huddleston J, Potter B, Callender C, Sagulenko P, Bedford T, Neher RA (2018) Nextstrain: real-time tracking of pathogen evolution. Bioinformatics 34(23):4121-4123

Harvey WT, Carabelli AM, Jackson B, Gupta RK, Thomson EC, Harrison EM, Ludden C, Reeve R, Rambaut A, Peacock SJ (2021) SARS-CoV-2 variants spike mutations and immune escape. Nat Rev Microbiol 19(7):409-424

Hoffmann M, Kleine-Weber H, Schroeder S, Krüger N, Herrler T, Erichsen S, Schiergens TS, Herrler G, Wu N-H, Nitsche A (2020) SARS-CoV-2 cell entry depends on ACE2 and TMPRSS2 and is blocked by a clinically proven protease inhibitor. Cell 181(2):271$280(\mathbf{e 8})$

Hou YJ, Chiba S, Halfmann P, Ehre C, Kuroda M, Dinnon KH, Leist SR, Schäfer A, Nakajima N, Takahashi K (2020) SARS-CoV-2 D614G variant exhibits efficient replication ex vivo and transmission in vivo. Science 370(6523):1464-1468

Hu J, He C, Gao Q (2020) D614G mutation of SARS-CoV-2 spike protein enhances viral infectivity. bioRxiv. Published online 2020(20.161323). https://doi.org/10.1101/2020.06.20.161323

Jackson CB, Zhang L, Farzan M, Choe H (2021) Functional importance of the D614G mutation in the SARS-CoV-2 spike protein. Biochem Biophys Res Commun 538:108-115

Janik E, Niemcewicz M, Podogrocki M, Majsterek I, Bijak M (2021) The emerging concern and interest SARS-CoV-2 variants. Pathogens 10(6):633

Jeyanathan M, Afkhami S, Smaill F, Miller MS, Lichty BD, Xing Z (2020) Immunological considerations for COVID-19 vaccine strategies. Nat Rev Immunol 20(10):615-632 
Korber B, Fischer W, Gnanakaran S, Yoon H, Theiler J, Abfalterer W, Foley B, Giorgi EE, Bhattacharya T, Parker MD (2020a) Spike mutation pipeline reveals the emergence of a more transmissible form of SARS-CoV-2. bioRxiv. https://doi.org/10.1101/2020.04. 29.069054

Korber B, Fischer WM, Gnanakaran S, Yoon H, Theiler J, Abfalterer W, Hengartner N, Giorgi EE, Bhattacharya T, Foley B (2020b) Tracking changes in SARS-CoV-2 spike: evidence that D614G increases infectivity of the COVID-19 virus. Cell 182(4):812-827. e19

Koyama T, Weeraratne D, Snowdon JL, Parida L (2020) Emergence of drift variants that may affect COVID-19 vaccine development and antibody treatment. Pathogens 9(5):324

Kwarteng A, Asiedu E, Sylverken AA, Larbi A, Sakyi SA, Asiedu SO (2021) Molecular characterization of interactions between the D614G variant of SARS-CoV-2 S-protein and neutralizing antibodies: a computational approach. Infection, Infect Genet Evol 91:104815

Leopold DR, Busby PE (2020) Host genotype and colonist arrival order jointly govern plant microbiome composition and function. Curr Biol 30(16):3260-3266 (e5)

Li Q, Wu J, Nie J, Zhang L, Hao H, Liu S, Zhao C, Zhang Q, Liu H, Nie L (2020) The impact of mutations in SARS-CoV-2 spike on viral infectivity and antigenicity. Cell 182(5):1284-1294 (e9)

Liu L, Wang P, Nair MS, Yu J, Rapp M, Wang Q, Luo Y, Chan JF-W, Sahi V, Figueroa A (2020) Potent neutralizing antibodies against multiple epitopes on SARS-CoV-2 spike. Nature 584(7821):450-456

Mahmoudi Gomari M, Rostami N, Omidi-Ardali H, Arab SS (2021) Insight into molecular characteristics of SARS-CoV-2 spike protein following D614G point mutation, a molecular dynamics study. J Biomol Struct Dyn 1-9. https://doi.org/10.1080/07391102. 2021.1872418

Mansbach RA, Chakraborty S, Nguyen K, Montefiori DC, Korber B, Gnanakaran S (2021) The SARS-CoV-2 spike variant D614G favors an open conformational state. Sci Adv 7(16):eabf3671

McCallum M, Bassi J, De Marco A, Chen A, Walls AC, Di Iulio J, Tortorici MA, Navarro M-J, Silacci-Fregni C, Saliba C (2021) SARS-CoV-2 immune evasion by the B. 1.427/B. 1.429 variant of concern. Science 373(6555):648-654

Mercatelli D, Giorgi FM (2020) Geographic and genomic distribution of SARS-CoV-2 mutations. Front Microbiol 11:1800

Mwenda M, Saasa N, Sinyange N, Busby G, Chipimo PJ, Hendry J, Kapona O, Yingst S, Hines JZ, Minchella P (2021) Detection of B. 1.351 SARS-CoV-2 Variant Strain-Zambia, December 2020. MMWR Morb Mortal Wkly Rep 70(8):280-282

. Ogawa J, Zhu W, Tonnu N, Singer O, Hunter T, Ryan AL, Pao GM (2020) The D614G mutation in the SARS-CoV2 Spike protein increases infectivity in an ACE2 receptor dependent manner. bioRxiv. https://doi.org/10.1101/2020.07.21.214932

Organization WH (2021) COVID-19 weekly epidemiological update, edition 43, 8 June 2021

Ostrov DA (2021) Structural Consequences of Variation in SARSCoV-2 B. 1.1. 7. J Cell Immunol 3(2):103

Ozono S, Zhang Y, Ode H, Sano K, Tan TS, Imai K, Miyoshi K, Kishigami S, Ueno T, Iwatani Y (2021) SARS-CoV-2 D614G spike mutation increases entry efficiency with enhanced ACE2-binding affinity. Nat Commun 12(1):1-9

Peters MH, Basidas O, Kokron D, Henze CE (2021) Transformations, lineage comparisons, and analysis of down to up protomer states of variants of the SARS-CoV-2 prefusion spike protein including the UK Variant B. 1.1. 7. bioRxiv. https://doi.org/10.1101/2021. 02.09.430519

Plante JA, Liu Y, Liu J, Xia H, Johnson BA, Lokugamage KG, Zhang X, Muruato AE, Zou J, Fontes-Garfias CR (2021) Spike mutation D614G alters SARS-CoV-2 fitness. Nature 592(7852):116-121
Salehi-Vaziri M, Jalali T, Farahmand B, Fotouhi F, Banifazl M, Pouriayevali MH, Larijani MS, Afzali N, Ramezani A (2021) Clinical characteristics of SARS-CoV-2 by re-infection vs reactivation: a case series from Iran. Eur J Clin Microbiol Infect Dis 40(8):1713-1719

Sanjuán R, Domingo-Calap P (2016) Mechanisms of viral mutation. Cell Mol Life Sci 73(23):4433-4448

Sharun K, Tiwari R, Dhama K, Emran TB, Rabaan AA, Al Mutair A (2021) Emerging SARS-CoV-2 variants: impact on vaccine efficacy and neutralizing antibodies. Hum Vaccin Immunother 17(10):3491-3494

Shi P-Y, Plante J, Liu Y, Liu J, Xia H, Johnson B, Lokugamage K, Zhang X, Muruato A, Zou J (2020) Spike mutation D614G alters SARS-CoV-2 fitness and neutralization susceptibility. Research Square. https://doi.org/10.21203/rs.3.rs-70482/v1

Shi Y, Wang Y, Shao C, Huang J, Gan J, Huang X, Bucci E, Piacentini M, Ippolito G, Melino G (2020) COVID-19 infection: the perspectives on immune responses. Cell Death Differ 5:1451-1454

Shu Y, McCauley J (2017) GISAID: Global initiative on sharing all influenza data-from vision to reality. Euro Surveill 22(13):30494

Slavov SN, Patané JSL, Bezerra RdS, Giovanetti M, Fonseca V, Martins AJ, Viala VL, Rodrigues ES, Santos EVd, Santos Barros CRd (2021) Genomic monitoring unveil the early detection of the SARS-CoV-2 B. 1.351 (beta) variant (20H/501Y. V2) in Brazil. J Med Virol https://doi.org/10.1002/jmv.27190.

Tegally H, Wilkinson E, Giovanetti M, Iranzadeh A, Fonseca V, Giandhari J, Doolabh D, Pillay S, San EJ, Msomi N (2021) Detection of a SARS-CoV-2 variant of concern in South Africa. Nature 592(7854):438-443

Volz E, Hill V, McCrone JT, Price A, Jorgensen D, O’Toole Á, Southgate J, Johnson R, Jackson B, Nascimento FF (2021) Evaluating the effects of SARS-CoV-2 spike mutation D614G on transmissibility and pathogenicity. Cell 184(1):64-75 (e11)

Wang P, Casner RG, Nair MS, Wang M, Yu J, Cerutti G, Liu L, Kwong PD, Huang Y, Shapiro L (2021) Increased resistance of SARSCoV-2 variant P. 1 to antibody neutralization. Cell Host Microbe 29(5):747-751 (e4)

Wang P, Liu L, Iketani S, Luo Y, Guo Y, Wang M, Ho D (2021) Increased resistance of SARS-CoV-2 variants B. 1.351 and B. 1.1. 7 to antibody neutralization. BioRxiv 25:428137

Wang Z, Schmidt F, Weisblum Y, Muecksch F, Barnes CO, Finkin S, Schaefer-Babajew D, Cipolla M, Gaebler C, Lieberman JA (2021c) mRNA vaccine-elicited antibodies to SARS-CoV-2 and circulating variants. Nature 592(7855):616-622

Weissman D, Alameh M-G, de Silva T, Collini P, Hornsby H, Brown R, LaBranche CC, Edwards RJ, Sutherland L, Santra S (2021) D614G spike mutation increases SARS CoV-2 susceptibility to neutralization. Cell Host Microbe 29(1):23-31 (e4)

West AP, Wertheim JO, Wang JC, Vasylyeva TI, Havens JL, Chowdhury MA, Gonzalez E, Fang CE, Di Lonardo SS, Hughes S, Rakeman JL, Lee HH, Barnes CO, Gnanapragasam PNP, Yang Z, Gaebler C, Caskey M, Nussenzweig MC, Keeffe JR, Bjorkman PJ (2021) Detection and characterization of the SARS-CoV-2 lineage B.1.526 in New York. Nat Commun 12(1):4886. https://doi. org/10.1038/s41467-021-25168-4

Wibmer CK, Ayres F, Hermanus T, Madzivhandila M, Kgagudi P, Oosthuysen B, Lambson BE, De Oliveira T, Vermeulen M, Van der Berg K (2021) SARS-CoV-2 501Y. V2 escapes neutralization by South African COVID-19 donor plasma. Nat Med 27(4):622-625

Wu K, Werner AP, Moliva JI, Koch M, Choi A, Stewart-Jones GB, Bennett H, Boyoglu-Barnum S, Shi W, Graham BS (2021) mRNA-1273 vaccine induces neutralizing antibodies against spike mutants from global SARS-CoV-2 variants. bioRxiv. https://doi. org/10.1101/2021.01.25.427948 
Xiong X, Qu K, Ciazynska KA, Hosmillo M, Carter AP, Ebrahimi S, Ke Z, Scheres SH, Bergamaschi L, Grice GL (2020) A thermostable, closed SARS-CoV-2 spike protein trimer. Nat Struct Mol Biol 27(10):934-941

Yurkovetskiy L, Wang X, Pascal KE, Tomkins-Tinch C, Nyalile TP, Wang Y, Baum A, Diehl WE, Dauphin A, Carbone C (2020) Structural and functional analysis of the D614G SARS-CoV-2 spike protein variant. Cell 183(3):739-751 (e8)

Zhang J, Cai Y, Xiao T, Lu J, Peng H, Sterling SM, Walsh RM, Rits-Volloch S, Zhu H, Woosley AN (2021) Structural impact on SARS-CoV-2 spike protein by D614G substitution. Science 372(6541):525-530

Zhang L, Jackson CB, Mou H, Ojha A, Peng H, Quinlan BD, Rangarajan ES, Pan A, Vanderheiden A, Suthar MS (2020a) SARS-CoV-2 spike-protein D614G mutation increases virion spike density and infectivity. Nat Commun 11(1):1-9

Zhang L, Jackson CB, Mou H, Ojha A, Rangarajan ES, Izard T, Farzan M, Choe H (2020b) The D614G mutation in the SARS-CoV-2 spike protein reduces $\mathrm{S} 1$ shedding and increases infectivity. bioRxiv doi: https://doi.org/10.1101/2020.06.12.148726
Zhang L, Ren Q, Yang J, Lu Y, Zhang L, Gai Z (2020c) Genomewide variations of SARS-CoV-2 infer evolution relationship and transmission route. medRxiv . https://doi.org/10.1101/2020.04. 27.20081349

Zhou B, Thao TTN, Hoffmann D, Taddeo A, Ebert N, Labroussaa F, Pohlmann A, King J, Steiner S, Kelly JN (2021a) SARS-CoV-2 spike D614G change enhances replication and transmission. Nature 592(7852):122-127

Zhou D, Dejnirattisai W, Supasa P, Liu C, Mentzer AJ, Ginn HM, Zhao Y, Duyvesteyn HM, Tuekprakhon A, Nutalai R (2021) Evidence of escape of SARS-CoV-2 variant B. 1.351 from natural and vaccine-induced sera. Cell 184(9):2348-2361 (e6)

Zhou T, Tsybovsky Y, Gorman J, Rapp M, Cerutti G, Chuang G-Y, Katsamba PS, Sampson JM, Schön A, Bimela J (2020) Cryo-EM structures of SARS-CoV-2 spike without and with ACE2 reveal a $\mathrm{pH}$-dependent switch to mediate endosomal positioning of receptor-binding domains. Cell Host Microbe 28(6):867-879 (e5)

Publisher's note Springer Nature remains neutral with regard to jurisdictional claims in published maps and institutional affiliations. 